\title{
INOVAÇÃO NA GESTÃO PÚBLICA: UM ESTUDO DO PRÊMIO INOVES
}

\author{
INNOVATION IN PUBLIC MANAGEMENT: A STUDY OF INOVES AWARD
}

\author{
Betânia de Laia Costa \\ Universidade Federal do Espírito Santo, ES, Brasil \\ E-mail: betaniadelaia@hotmail.com \\ Susane Petinelli Souza \\ Universidade Federal do Espírito Santo, ES, Brasil \\ E-mail: susipetinelli@gmail.com
}

Recebido em: 08.07.2019 - Aceito em: 24.11.2019

DOI: http://dx.doi.org/10.5902/2526629238939

\section{RESUMO}

Este estudo objetivou analisar o Prêmio Inoves como potencializador de iniciativas de inovação na gestão pública. Para isso, a ideia de inovação vem apoiada na administração pública gerencial. Os dados empíricos foram produzidos por meio de pesquisa documental e entrevistas semiestruturadas. No total, foram entrevistados 19 servidores públicos. Quanto aos procedimentos de análise dos dados, o trabalho utiliza a análise de conteúdo. Os resultados apontam que as mudanças ocorridas no universo do trabalho na gestão privada atingem o setor público, considerado muitas vezes ineficiente e oneroso. Pode-se dizer que o Inoves potencializa iniciativas de inovação na gestão pública premiando e reconhecendo práticas inovadoras, tendo como foco a multiplicação dessas práticas. Apesar do setor público apresentar ações que valorizam boas práticas dos servidores, como o Prêmio Inoves, para a maioria dos entrevistados ainda há uma carência por parte do governo em ações de reconhecimento do trabalho do servidor. A relevância desta pesquisa é contribuir para o enriquecimento dos estudos sobre inovação no setor público num nível micro de análise.

Palavras-chave: Inovação; Gestão pública; Administração pública gerencial; Prêmio Inoves.

\section{ABSTRACT}

The aim of this study is to analyze the Inoves award as an effective tool for the innovative initiatives in public administration. Therefore, the idea of innovation has as its support the manager public administration. Empirical data were produ- 
ced by means of a documental research as well as semi structured interviews. In all, were interviewed 19 civil servants. Data were analyzed in this study by means of the content analysis methodology. Results point out that changes occurring in the private administration work spaces are extended to the public sector, which is very often considered inefficient and onerous. One may say that Inoves has strengthened innovation initiatives for the public administration, identifying and conferring awards to innovative practices, which aim to the multiplication of such practices. Although the public sector has carried out actions which value the civil servants' good practices, such as the Inoves award, for the majority of the people interviewed, the government has not yet met the expectations of the civil servants for actions which truly recognize the importance of their work. The relevance is that this investigation will contribute to the advance of the study of innovation in the public sector at a micro level of analysis.

Keywords: Innovation; Public management; Manager public administration; Inoves award.

\section{INTRODUÇÃO}

Com o tempo, o Estado necessitava ampliar seu papel econômico e social, e a estratégia da administração pública burocrática apresentava-se inadequada, com muitos procedimentos formais e rígidos controles hierárquicos (Bresser-Pereira, 1998). Assim, apresentaram-se na administração pública alguns procedimentos gerenciais próprios das organizações privadas ao contexto público, num processo de tentativa de substituição da abordagem de cunho burocrático. Nesse sentido, Santos $(2017,2018)$ pontua que há uma convergência da administração pública para um modelo pautado no gerencialismo.

Nessa conjuntura, a inovação se apresenta como uma das características da administração pública gerencial, pois o gerencialismo no setor público serve-se do incentivo à inovação (Bresser-Pereira, 1998).

O objetivo desse estudo é analisar o Prêmio Inoves como potencializador de iniciativas de inovação na gestão pública do Espírito Santo. Para tanto, foi necessário caracterizar o Prêmio Inoves; descrever uma iniciativa de inovação premiada e analisar o Inoves como uma iniciativa de reconhecimento e valorização do servidor público. O Prêmio veicula a ideia na qual defende contribuir para a modernização da administração pública, num forte discurso de inovação ancorado na administração pública gerencial. 


\section{REFERENCIAL TEÓRICO}

\subsection{Inovação no setor público}

Pode-se dizer que a filosofia do NPM (New Public Management) apresenta uma combinação de um alto grau de autonomia de gestão e o controle fundamentado nos resultados, com o propósito de aumentar a eficiência e a eficácia (Hondeghem \& Dorpe, 2013). Hansson, Norn \& Vad (2014) asseguram que a nova gestão pública reformou o setor público e, nas últimas décadas, vários países usaram diferentes ferramentas de New Public Management com o propósito de modernizar os serviços das instituições públicas.

A partir de 1995, o governo federal criou o Ministério da Administração Federal e Reforma do Estado. Nomeado como ministro, Luiz Carlos Bresser Pereira se torna o autor e defensor de um processo de reestruturação do Estado, denominado como administração pública gerencial, que incluía reformas de cunho administrativo, previdenciário e político (Bresser-Pereira, 2000).

Para Bresser-Pereira (2000), a reforma gerencial buscou superar a maneira patrimonialista de gerenciar o Estado, que, embora inerte como valor, não foi totalmente eliminada. Buscou também criticar e propor um viés gerencial à administração pública burocrática. Desse modo, segundo o autor, se fortaleceu no Brasil a nova gestão pública, intitulada de administração pública gerencial. Diversas ações com fins específicos foram propostas com o objetivo de que o modelo burocrático fosse repensado, adotando um conjunto de medidas para tornar mais ágil e eficaz a máquina pública estatal.

Segundo Motta (2013), desde o século XIX busca-se assemelhar a administração pública à gestão privada. Para o autor, esse era o objetivo primordial do New Public Management, que espalhou essa ideia no século XX, propondo fazer com que a administração pública operasse como uma empresa privada, para reduzir custos, adquirir eficiência e alcançar maior eficácia na prestação dos serviços.

Silva, Macedo e Andrade (2013) pontuam que, no governo federal de 2003 a 2010, buscou-se a continuação das iniciativas das experiências anteriores da administração pública gerencial e o estímulo a um processo de revitalização do Estado, propondo a diminuição das desigualdades. Valores de eficiência e qualidade na prestação dos serviços públicos se evidenciaram, buscando incentivar práticas do setor privado. 
No setor púbico, percebe-se a implementação de práticas de modelos de gestão organizacional voltadas ao empreendedorismo, num incentivo às ideias da excelência organizacional, estimulando trabalhadores receptivos à mudança, incomodados com a rotina e a previsibilidade no trabalho. Esse arquétipo do trabalhador-padrão é ideal para satisfazer à estrutura flexível de organizações modernas, um modelo para os donos do capital (Ribeiro \& Mancebo, 2013).

Sousa et al. (2013) pontuam que as normas, a cultura e as condições legais no âmbito institucional podem representar restrições ou incentivos à inovação no setor público. Esses autores assinalam que, para a existência dessa renovação, faz-se necessário um meio que possibilite liberdade para o desenvolvimento do processo de inovação junto aos colaboradores, todavia, o setor público é fortemente caracterizado pela existência de normas que limitam ações inovadoras.

No contexto público, o empreendedorismo relaciona-se à adoção de técnicas de proatividade e inovação pelos agentes responsáveis (Teixeira et al., 2019). Hughes, Moore \& Kataria (2011) recomendam o entendimento de inovação como: a inserção de uma transformação expressiva no modo de operar a organização ou mesmo nos produtos ofertados. Para os autores, as inovações abrangem produtos, serviços, métodos ou processos que sejam novos ou aperfeiçoados. Assim, acreditam que mesmo que a inovação tenha sido concebida por outros, importa que seja nova para a organização. No mesmo sentido, Walker, Damanpour e Devece (2010), além de Beinare e Mccarthy (2011), salientam que a inovação deve ser nova para o estado da arte ou ao menos para o contexto organizacional.

Para Brandão e Bruno-Faria (2013), sob o ponto de vista social, um setor público inovador pode garantir uma melhor relação com os cidadãos na medida em que oferece produtos e serviços de qualidade, pois conforme pontua Teixeira et al. (2019), no setor público, o foco é o bem comum. Sob o ponto de vista econômico, Potts e Kastelle (2010) apresentam alguns motivos para o incentivo da inovação no setor público: O setor público é um elemento expressivo da macroeconomia, colaborando entre $20 \%$ e $50 \%$ do PIB (Produto Interno Bruto) na maioria dos países da Organização para Cooperação e Desenvolvimento Econômico (OCDE); o setor público é responsável por fornecer serviços às empresas e aos cidadãos e a inovação é capaz de possibilitar novos modos de solução de problemas.

\subsection{Reconhecimento e valorização do servidor}

Ribeiro e Mancebo (2013) expõem que a falta de reconhecimento e valorização influencia no sentido dado pelos servidores públicos à sua vida profissional. 
Por isso, a recompensa do trabalho não é somente a estabilidade financeira; o trabalho surge como uma fonte de prazer, quando há espaço para o reconhecimento social da contribuição humana.

Percebe-se que o reconhecimento pelo trabalho realizado é uma questão importante na vida do trabalhador, sendo entendido como uma contrapartida pelo empenho realizado (Bendassolli, 2012), o que não é diferente na vida do servidor público. Uma vez que o Inoves premia práticas inovadoras, faz-se relevante analisar, a partir da percepção dos membros participantes, essa premiação como uma iniciativa de reconhecimento e valorização do servidor público.

Em conformidade com isso, Borins (2001) afirma que, quando as inovações são causadas por gerentes de linha de frente ou de nível intermediário, o apoio dos líderes e dirigentes é fundamental para o sucesso da inovação. Ainda buscando analisar as principais características de inovações premiadas em concursos de países como Estados Unidos e Canadá, o autor pontua que, apesar do setor público normalmente ser considerado não receptivo a inovações, algumas evidências revelam que muitas inovações são ocasionadas graças ao pessoal de linha de frente e aos gerentes de nível intermediário.

A valorização de práticas inovadoras e o reconhecimento por parte do governo aos servidores inovadores podem resultar em ganhos para toda a sociedade, visto que a valorização do servidor possibilita certo estímulo aos servidores e, por consequência, uma maior qualidade na prestação dos serviços públicos (Silva, Macedo, \& Andrade, 2013).

\section{MÉTODO DE PESQUISA}

Quanto aos procedimentos de coleta de dados, a pesquisa classifica-se como qualitativa, pois, conforme Bauer, Gaskell e Allum (2002), a pesquisa qualitativa trabalha com explicações das realidades sociais e segundo Yin (2016), abrange um agrupamento de orientações, com diferentes interpretações do mesmo evento.

Os sujeitos da pesquisa foram definidos, conforme a relevância dos indivíduos, por poderem contribuir com a compreensão do Prêmio, a fim de enriquecer os dados e possibilitar o entendimento do estudo em questão. Dessa forma, os participantes da pesquisa foram pessoas ligadas à equipe responsável pelo Prêmio Inoves: O secretário à época da implantação do Prêmio (em 2005); o secretário responsável pela Secretaria de Estado de Gestão e Recursos Humanos, 
órgão vinculado ao Prêmio; o coordenador e três pessoas que compõem a equipe responsável pelo programa, sujeitos definidos na pesquisa como Equipe Prêmio Inoves. Foram realizadas entrevistas semiestruturadas, definidas a partir de perguntas abertas.

Também foi possível analisar uma das iniciativas de inovação premiadas, além dos avaliadores da premiação. Dessa forma, optou-se por entrevistar dois avaliadores que tivessem participado em mais de um ciclo do Prêmio. Os dados foram coletados também por meio de pesquisa documental, tanto de divulgação eletrônica quanto impressa.

A metodologia de pesquisa utilizada para a análise dos dados foi a Análise de Conteúdo (AC). Franco (2003, p. 13) destaca que "o ponto de partida da Análise de Conteúdo é a mensagem, seja ela verbal (oral ou escrita), gestual, silenciosa, figurativa, documental ou diretamente provocada". Neste trabalho, escolheu-se utilizar a categorização a posteriori. Após a transcrição das entrevistas, o critério de categorização utilizado foi o semântico, realizando a codificação por temas (Bardin, 2004), o que possibilitou uma compreensão dos elementos relevantes.

As categorias da pesquisa surgiram inspiradas pelo conteúdo do material que compõe o corpus da mesma, em consonância com a problemática teórica (Colbari, 2014). As categorias para a análise dos dados foram criadas buscando ir além do texto e dos aspectos linguísticos do conteúdo que emergiu das falas dos indivíduos e do material coletado. Assim, foram definidas as categorias que se destacaram nas falas da Equipe responsável pelo Prêmio Inoves, Avaliadores e Equipe Premiada.

A pesquisa concentrou-se num nível micro de análise, priorizando os indivíduos, numa análise mais particularizada. Assim, ficam excluídas nessa pesquisa análises no nível meso e macro, que priorizam respectivamente organizações e suas subunidades, e conjunto de organizações (Lima \& Vargas, 2012; Hansson, Norn, \& Vad, 2014).

\section{APRESENTAÇÃO E DISCUSSÃO DOS RESULTADOS}

\subsection{Histórico e Caracterização do Prêmio Inoves}

$\mathrm{Na}$ década de noventa, havia uma diretriz governamental na tentativa de institucionalizar a qualidade no setor público por meio da Coordenação Estadual da Qualidade. Havia, também, um movimento espontâneo de servidores públicos nessa temática, denominado de Movimento Pró-qualidade. Existia ainda uma Cooperativa de Qualidade que visava discutir o assunto. Em 1995 (governo 
Vitor Buaiz), foi apresentada uma proposta escrita por participantes do Movimento Pró-qualidade para um novo programa de qualidade do governo denominado PIQ (Programa Iniciativas da Qualidade na Gestão Pública do Espírito Santo). Em 1996, o governador lança esse programa e institucionaliza o Movimento Pró-qualidade chamando-o de Fórum Governamental da Qualidade (FGQ) e cria uma representatividade entre todas as organizações públicas, de modo que existissem dois representantes de cada organização pública, tanto da administração direta quanto da administração indireta para compor esse fórum.

Em 2004, no governo de Paulo Hartung, o FGQ deixou de existir com a junção das Secretarias de Administração e a de Planejamento, que se tornou Planejamento Orçamento e Gestão. Em 2005, separam-se novamente as secretarias, para Planejamento e a da Administração foi transformada em Gestão. Com a nova Secretaria de Gestão, é criado um prêmio de inovação, fundamentado em experiências anteriores obtidas em outros estados da União. Assim, cria-se o Prêmio de Inovação na Gestão Pública do Espírito Santo, o Prêmio Inoves.

O conceito inicial do Prêmio era valorizar iniciativas inovadoras, que não eram identificadas e nem incentivadas pela gestão, de maneira a envolver os servidores no governo e que as iniciativas fossem referências para os demais. Com o tempo, o Prêmio passou a ser um programa de inovação na gestão pública. $O$ Prêmio Inovação na Gestão Pública do Espírito Santo (Prêmio Inoves) trata-se de um programa do governo do estado do Espírito Santo, criado em 2005, coordenado pela Secretaria de Estado de Gestão e Recursos Humanos (SEGER).

Dentre os possíveis participantes do Prêmio estão os projetos formulados por equipes de trabalho inseridas no contexto do serviço público municipal e estadual dos três poderes (Legislativo, Executivo e Judiciário), do Tribunal de Contas, bem como do Ministério Público do Espírito Santo.

O Prêmio propõe estimular o desenvolvimento da inovação e do empreendedorismo no cenário do serviço público, realçando e premiando trabalhos considerados inovadores, concebidos por servidores públicos capixabas, suscetíveis de modificar a realidade e melhorar a vida do usuário do serviço público, buscando, assim, modernizar a administração pública. "Só é possível atender aos desejos da população se tivermos servidores inovadores, capazes de encontrar soluções simples para os mais diversos problemas e garantir qualidade no atendimento aos cidadãos capixabas" (Um..., 2013, p. 8).

Apresenta-se como objetivo do Prêmio o reconhecimento de resultados produzidos por iniciativas de servidores públicos, capazes de gerar serviços públicos de qualidade, que reduzam gastos e propiciem satisfação para a sociedade 
por meio da inovação, tendo como foco também a multiplicação dessas ideias inovadoras.

É o efeito multiplicador desse trabalho que tanto desejávamos e que, hoje, começamos a enxergar no Espírito Santo. O comprometimento e as boas práticas de servidores capixabas reconhecidas e incentivando outros servidores locais, servindo de exemplo para outros cantos do Brasil (Editorial, 2006, p. 3).

O Prêmio Inoves (acesso em 12 abr. 2019) divulga em seu site que já concorreram mais de 2 mil projetos inovadores, desde 2005, nas várias categorias existentes. Foram 225 trabalhos que obtiveram reconhecimento a nível nacional e estadual, após a premiação, servindo de modelo para outros setores, sistemas de trabalho ou mesmo organizações.

Os projetos inscritos no Prêmio devem ter mais de seis meses de implantação e apresentar resultados objetivos verificáveis decorrentes das práticas inovadoras. As equipes devem ser compostas de, no mínimo, dois e, no máximo, oito servidores públicos envolvidos (efetivos, comissionados, ou designação temporária). Cada trabalho indicado deverá pertencer a uma única categoria para a qualificação dos projetos. A premiação e o reconhecimento dos projetos indicados ocorrerão para os trabalhos que apresentarem resultados considerados mais expressivos. Assim, cada categoria do Prêmio terá um premiado com maior pontuação.

Compõem a banca examinadora do Prêmio: especialistas com reconhecida atuação ou pesquisa em gestão, políticas públicas e sociais, especialistas e pesquisadores na área de Tecnologia da Informação e Comunicação, Governo Eletrônico e Gestão, selecionados, convidados e gerenciados pela Coordenação Executiva do Prêmio. A participação do membro da banca examinadora não é remunerada e sua decisão não é suscetível de impugnação ou recurso.

No ciclo 2018, último ciclo premiado, para a qualificação dos projetos inscritos, observou-se as seguintes categorias: categoria Ideia, categoria Projeto em Desenvolvimento e a categoria Projeto de Resultados (Inoves, 2019). Entretanto, no momento da pesquisa, o Prêmio Inoves apresentava oito categorias para a qualificação dos projetos: Desburocratização, Uso eficiente dos Recursos Públicos, Valorização do Servidor, Atendimento ao Cidadão, Resultados para a Sociedade, Inclusão Social, Participação e Controle Social, e Uso das Tecnologias de Informação e Comunicação.

No ciclo 2013, ano da iniciativa de inovação premiada foco deste estudo, a premiação de cada equipe foi caracterizada por um troféu; um certificado de reconhecimento e premiação; um kit de equipamento de informática, padronizado 
para todas as equipes ganhadoras, contendo desktop, notebook e tablet, no valor máximo de quinze mil reais; outdoor com foto da equipe premiada colocado em local próximo à unidade onde a coordenação da equipe ganhadora atua e publica na Revista Inoves, de matéria sobre o projeto ganhador.

A iniciativa de inovação premiada e analisada foi o projeto ISS Online, também chamado ISISS (Internet Sistema de Imposto Sobre Serviço), premiado no ciclo 2013, desenvolvido no município de Vitória, por uma equipe da Secretaria Municipal de Fazenda. O ISS Online é um sistema de declarações eletrônicas de imposto sobre serviço, e busca facilitar o pagamento do ISS (Imposto Sobre Serviço), permitindo um maior controle para o município.

O ISS Online foi vencedor na categoria denominada desburocratização. Esse projeto, implementado com obrigatoriedade no município de Vitória a partir de 2005, buscou a agilidade no processo para o pagamento do imposto e o combate à sonegação. "Sem um sistema próprio de controle do ISS, o município não tinha informações precisas sobre as empresas que prestavam e tomavam serviços em Vitória" (Menos..., 2013, p. 20).

A partir de 2005, as declarações passaram a ser mensais e diretamente no sistema. Através da internet a empresa declara os serviços prestados e o movimento econômico tributável. Desta forma, tanto o contribuinte quanto a fiscalização podem, a qualquer tempo, entrar no sistema e acessar o livro fiscal da empresa. "A ideia do projeto foi o município ter um controle sobre a capacidade instalada dentro do município, tanto de prestação de serviço quanto de empresas, de serviços tomados" (Entrevistado Q).

A implantação do ISS Online reduziu a necessidade de ter que se deslocar à prefeitura para escriturar o livro fiscal da empresa, que passou a ser feito eletronicamente e de forma automática, e reduziu o consumo do papel, pois o pagamento das guias de recolhimento do imposto também pode ser feita eletronicamente. Outro benefício foi o aumento na arrecadação do ISS, "houve um acréscimo de 37\% ao ano no recolhimento de imposto", nos dois primeiros anos de implantação. Já, "se considerado o crescimento acumulado, de janeiro de 2004 a janeiro de 2013, esse percentual chega a 259\%”. Apesar de outras medidas e ações fiscais adotadas pelo governo, acredita-se que o sistema contribuiu para esse acréscimo (Menos..., 2013, p. 20). Esse projeto alavancou outro projeto: Da Nota Fiscal Eletrônica, criado também pelo município de Vitória, na qual a maioria das empresas é obrigada a emitir tal nota.

O banco de dados do ISS Online abarca mais de sessenta e três mil contribuintes capacitados a utilizar o sistema, possuindo um registro superior a dois milhões de declarações realizadas em Vitória. Em 2007, esse sistema foi instalado 
também em Vila Velha e possui convênios firmados para a implantação em outros municípios do Estado e fora do Estado do Espírito Santo (Menos..., 2013).

\subsection{Análise dos dados}

\subsubsection{Redução dos entraves burocráticos}

A crítica ao exagero dos procedimentos burocráticos ponderados na administração pública gerencial, devido ao excesso de normas, formalismo, lentidão nos processos, dentre outros (Bresser-Pereira, 1998), é um dos aspectos percebidos na pesquisa. Sousa e outros (2013) pontuam que o setor público é profundamente caracterizado pela existência de restrições como normas e condições legais que limitam ações inovadoras. E para a existência de inovação faz-se necessário um meio que possibilite liberdade para o desenvolvimento desse processo.

Para o Entrevistado C da Equipe Prêmio Inoves, apesar do intento em meIhorias, o excesso de procedimentos burocráticos existentes na administração pública impede que demonstre avanços e divulgue uma boa imagem do setor público à população. Outro entrevistado, avaliador do Prêmio, pondera:

Chegamos à conclusão de que a categoria desburocratização já ficou ultrapassada, porque um serviço que seja burocratizado não pode ser considerado inovador. A gente entendeu a desburocratização como obrigação de todo projeto." (Entrevistado G). Percebe-se que há um estímulo desse programa em desburocratizar a gestão pública. A categoria desburocratização que existia para a qualificação dos projetos inscritos até o ciclo de 2013, a partir de 2014 deixa de existir e passa a ser incorporada indiretamente por todas as demais.

Para o Entrevistado R, o sistema ISS Online proporcionou a redução da burocracia "do pedido de documentos fiscais e a declaração desses documentos pelos prestadores de serviço", trazendo maior agilidade, pois o sistema agrega diversas informações que antes manualmente não se conseguiria, ou ao menos, havia uma demora para a obtenção das informações. Atualmente, consegue-se "saber exatamente a movimentação de nota fiscal, quais são as atividades" desenvolvidas pela empresa, pois tudo está no sistema (Entrevistado S). Para o Entrevistado R:

Com o ISS online isso tudo passou a ser online, pelo computador. Hoje, associado à nota fiscal eletrônica ele não precisa pedir para imprimir notas fiscais, porque a nota fiscal é eletrônica, ele preenche a nota na internet e a declaração disso também é pela internet, porque as notas já estão no sistema, então ele mesmo contabiliza. 
A partir do momento em que "emitiu a nota fiscal, automaticamente já vai compondo o livro fiscal da empresa". Cabe acrescentar que, "ao contrário do que se pensava no início do projeto, o sistema não tirou o trabalho do fiscal" (Entrevistado Q).

Segundo o Entrevistado D, atualmente a desburocratização trata-se de um dever do Estado, "entende-se hoje que é uma obrigação do Estado desburocratizar e antes não era". Para esse entrevistado, as demandas existentes na atualidade têm estimulado processos desburocratizantes no setor público.

Nas falas da Equipe Prêmio Inoves e dos avaliadores pode-se notar que é importante que um projeto inovador tenha a redução de entraves burocráticos, como maior rapidez na gestão dos processos e redução do excesso de formalismos. Por outro lado, os premiados também acreditam na importância dos modos de trabalho, dada a constatação de que, por vezes, o excesso de controle e de procedimentos burocráticos podem servir como um obstáculo com relação aos projetos inovadores.

Para Wodecka-Hyjek (2014), o discurso contemporâneo destaca a necessidade de criação de inovação nas organizações públicas. O Prêmio Inoves segue o fluxo na tendência em implementar inovação em organizações do setor público. $O$ Inoves busca o estímulo à redução da burocracia na administração pública gerencial, dirigida para a eficácia e o desempenho organizacional, com uma abordagem direcionada para o cidadão-cliente.

\subsubsection{Reconhecimento do servidor e estímulo à inovação}

Frente às exigências do universo do trabalho, especialmente na lógica do trabalhador autônomo e empreendedor, Ribeiro e Mancebo (2013) pontuam a importância dos servidores públicos serem reconhecidos e valorizados no ambiente de trabalho. $O$ desígnio desse reconhecimento aparece entre as razões que impulsionam a participar do Prêmio.

Para o Entrevistado K, o reconhecimento do serviço prestado é a principal importância do prêmio, uma vez que a premiação destaca e valoriza os servidores que "estão fazendo a diferença". Por meio das entrevistas e dentre os objetivos expostos pelo Prêmio, do material coletado, o reconhecimento de resultados reais produzidos por servidores inovadores está como o principal objetivo do programa, sendo considerado pela maioria dos entrevistados como o fator relevante para concorrer à premiação. $\mathrm{O}$ Entrevistado $\mathrm{F}$, da Equipe Prêmio Inoves, ratifica que o fato do Prêmio Inoves promover o reconhecimento dos bons trabalhos realizados pelos servidores públicos é um incentivo aos servidores a concorrerem ao prêmio. 
Para Chanlat (2002), a motivação para o trabalho no serviço público é algo importante, visto que, muitas vezes, este trabalho é associado a uma imagem negativa, de que os funcionários estariam pouco dispostos a trabalhar e preocupados com vantagens e privilégios. Percebeu-se que, dentre os entrevistados, a motivação em desenvolver projetos inovadores parte do interesse pessoal. Os relatos dos servidores premiados ressaltam que carecem de incentivo por parte do governo para práticas inovadoras.

"As questões são pessoais, institucionais é muito difícil, falo deles aqui, do próprio governo, quer dizer, são atitudes pontuais de pessoas mesmo, não é a política do estado, essa é a maior dificuldade." (Entrevistado O, grifo nosso)

Durante as entrevistas, perceberam-se discursos de servidores interessados em inovar e fazerem a diferença no setor público, instigando melhorias no trabalho. Para os entrevistados, a ideia da inovação está se disseminando no setor público. O Entrevistado F afirma que "o Prêmio serviu para disseminar essas práticas inovadoras no serviço público".

O Entrevistado Q não percebe ações no setor público capazes de motivar a inovação, entretanto, cita que "o prêmio Inoves é altamente motivador pra quem participa". Para este, as inovações ocorrem particularmente por conta do interesse pessoal em querer contribuir para melhorias no setor público e, dependendo do perfil da gestão, podem ocorrer impulsos para o aprimoramento no trabalho, com benefícios para toda a sociedade.

Dentre os motivos apresentados por Potts e Kastelle (2010) para o incentivo à inovação no setor público, está a capacidade da inovação possibilitar a obtenção de consequências positivas por meio de novos modos de solução de problemas, uma vez que o setor público é responsável por fornecer serviços à sociedade. Dessa forma, faz-se necessário que isso seja estimulado em todos os níveis hierárquicos. A maioria dos entrevistados diz não perceber estímulo por parte da administração pública no que diz respeito à inovação, buscando melhorias no setor público, acreditando serem ações isoladas, não sistematizadas. Por outro lado, um dos entrevistados percebe o Prêmio como um estímulo à inovação: "Ele é uma forma de ver que seu trabalho foi reconhecido, foi valorizado. E isso, no meu entendimento, estimula a conquista de um prêmio, em especial o Prêmio Inoves, eu acredito que seja um grande incentivo pra gente continuar e assim perceber "poxa, tô no caminho certo, e te aguçar a procurar, desenvolver mais coisas" (Entrevistado I).

Os projetos premiados no Inoves apresentam o fato de serem algo novo para a organização, mesmo que já existente em outros lugares (Hughes, Moore, \& Kataria, 2011). O Entrevistado F diz que: 
O Prêmio descobriu empreendedores pelo estado inteiro, não que o Prêmio criou, mas eles estão aí, independente de serem reconhecidos ou não, eles estão aí, empreendendo coisas, sendo inovadores. Claro, se você descobre essas pessoas por conta do Prêmio, joga luz em cima delas, esse exemplo é um exemplo a ser seguido por outros.

Percebeu-se nas entrevistas que o projeto premiado adveio de servidores de linha de frente ou gerentes de nível intermediário, com características de líderes, que perceberam a necessidade de mudança e buscaram inovar no trabalho, sendo essencial o apoio desses líderes e dirigentes para o sucesso da inovação, como pontuado por Borins $(2000,2001)$.

4.2.3 Práticas de gestão do âmbito privado utilizadas na gestão pública

Conforme Bresser-Pereira (2000), a administração pública gerencial busca inspiração na administração das empresas privadas para gerenciar com eficiência o setor público. Nesse sentido, na análise dos dados foram observadas algumas práticas e ferramentas típicas do setor privado utilizadas no setor público.

A qualidade na prestação dos serviços públicos é evidenciada pelo Prêmio, buscando incentivar práticas do setor privado (Silva, Macedo, \& Andrade, 2013). Para os Entrevistados, a carência na prestação de serviços de qualidade é algo a ser combatido pelo Prêmio.

Outro aspecto percebido por alguns projetos inovadores premiados no Inoves referem-se à busca de uma nova maneira, por meio de uma nova tecnologia para a realização de um processo (Abreu, 1994), visando obter o máximo desempenho com a utilização dessa nova tecnologia, como exemplo o ISS Online, que implantou um sistema para o pagamento do imposto sobre serviços na prefeitura de Vitória.

O trabalho em equipe evidenciado por Carvalho (2009) na prática da gestão moderna é um ponto chave do Prêmio, visto que todos os projetos inscritos devem ser formados por equipes compostas de dois a oito servidores envolvidos. $\mathrm{O}$ Entrevistado D, da Equipe Prêmio Inoves, assegura: "O nosso trabalho pessoal é fomentar o trabalho em equipe entre os servidores, a gente não quer individualizar ninguém dentro desse projeto, quer fomentar mesmo o trabalho em equipe".

A cooperação, a participação e o trabalho em equipe são relevantes na administração pública gerencial, podendo colaborar para a democratização das relações no trabalho (Carvalho, 2009). Entretanto, a limitação dos participantes na equipe é questionada por alguns premiados. 
Pode-se dizer que, tanto para a Equipe Prêmio Inoves, quanto para a equipe premiada, foram percebidas diversas práticas de gestão, próprias do âmbito privado, sendo aplicadas no setor público.

\subsubsection{Dificuldades para inovar}

Diversas restrições existentes no setor público foram percebidas nos projetos inovadores pesquisados, como servidor, tecnologia, resistência interna, balizas jurídicas e outras que restringem a facilidade de rápidas mudanças, quando comparadas à situações para inovação no setor privado (Hansson, Norn, \& Vad, 2014), gerando dificuldades na implantação das inovações nos ambientes de trabalho.

O Entrevistado $S$ afirma que existem diversas dificuldades para se inovar no âmbito público, como a não institucionalização do processo de melhoria, pois nem sempre o servidor público tem tempo para se dedicar ao projeto inovador, há por vezes mudanças de servidores nos locais de trabalho, bem como dificuldades de tecnologia e infraestrutura.

Nesse caso relatado, apesar das dificuldades apresentadas, percebeu-se que com o empenho de poucas pessoas criou-se um sistema de atendimento, com a iniciativa de tornar prática para o cidadão a prestação do serviço na declaração e trazer benefícios para a administração, especialmente com relação aos mecanismos de controle do imposto (ISS).

Contudo, houve resistências internas, como relatado pelo Entrevistado Q: "a nossa maior resistência foi interna na época, porque a visão que se tinha na área de fiscalização era de que o sistema ia tirar o trabalho do fiscal, e na verdade não ia, e eles perceberam isso."

Segundo os participantes da equipe premiada, diversos obstáculos foram evidenciados para se inovar no ambiente de trabalho. As dificuldades para se resolverem com rapidez as questões da sociedade (Motta, 2013) e no âmbito da gestão pública podem atrapalhar as possíveis melhorias de inovação no setor público.

Sabe-se que as inovações, independente da esfera relacionada, pública ou privada, podem ocasionar questionamentos e entraves em sua implementação. Contudo, as restrições existentes no setor público relatadas pelos entrevistados na pesquisa confirmam a dificuldade de se inserir inovação nesse setor, uma vez que restringem a facilidade de mudanças (Hansson, Norn, \& Vad, 2014).

Apesar do setor público não ter como hábito incentivar práticas inovadoras por meio de premiações e benefícios em dinheiro (Rosenblatt, 2011), percebe-se 
o Prêmio Inoves indo ao encontro dessa lacuna apresentada, visto que é um programa que premia projetos inovadores na gestão pública, por meio de premiações e benefícios que são repartidos entre a equipe vencedora, ainda que careça de retribuições pecuniárias aos vencedores.

Em conformidade com Sousa et al. (2013) acredita-se que o incentivo à inovação no âmbito público tem aumentado, devido aos prêmios e concursos promovidos por organizações governamentais. Sousa et al. (2015) também constatam que apesar da maior incidência de inovações ocorrerem em nível nacional, há um número significativo em nível local. Entretanto, percebeu-se entre os premiados, que o setor público ainda necessita de meios que incentivem experiências inovadoras na gestão.

Os dados obtidos na pesquisa evidenciam que há carência de política de inovação na administração pública capixaba, pois, para os entrevistados, as organizações não estimulam iniciativas inovadoras. Dessa forma, o Inoves se apresenta como um programa do governo que propõe incentivar a inovação por meio do reconhecimento de projetos inovadores.

A iniciativa de inovação premiada mostrou-se de acordo com os conceitos de inovação apresentados por Walker, Damanpour e Devece (2010), entendendo a inovação dos projetos premiados como o desenvolvimento ou a adoção de novas práticas e ideias, resultando em novos produtos, serviços e práticas

As mentalidades e ferramentas utilizadas no âmbito privado revelaram-se em voga no setor público. Desta forma, o Prêmio demonstrou características da administração pública gerencial, corroborando a afirmativa de Bresser-Pereira (2000), que pontua que a administração pública gerencial busca inspiração na administração das empresas privadas para gerenciar com eficiência o setor público.

\section{CONSIDERAÇÕES FINAIS}

Esta pesquisa analisou o Prêmio Inoves como potencializador de iniciativas de inovação na gestão pública. Percebeu-se um incentivo à inserção, na administração pública de concepções gerenciais, típicas da administração privada, como o estímulo ao empreendedorismo e à inovação. Além disso, verificou-se que o Inoves busca contribuir para a valorização do servidor, com o incentivo ao reconhecimento de práticas inovadoras na gestão.

Analisou-se, a partir da percepção dos membros participantes, equipe de governo, avaliadores e equipe premiada, como o Inoves se constitui numa iniciativa de reconhecimento e valorização do servidor público. Pode-se dizer que, para 
os participantes da pesquisa, a premiação do Inoves é fundamental no estímulo à inovação, pois, não apenas o valor em espécie alcançado ou os equipamentos adquiridos com a premiação, mas se percebeu o Inoves como uma motivação emocional para o servidor continuar inovando.

Apesar do setor público apresentar ações que valorizem boas práticas dos servidores, para a maioria dos entrevistados, ainda há uma carência por parte do governo em ações de reconhecimento do trabalho do servidor. Ainda assim, pode-se dizer que o Inoves fortalece e estimula a inovação premiando e reconhecendo práticas inovadoras que deram certo no setor público, tendo como foco a multiplicação dessas práticas.

Em conformidade com Castro et al. (2017), Santos, Sano e Souza (2019), pode-se dizer, também, que há uma carência de estudos brasileiros que pontuam antecedentes da inovação no setor público. Dessa forma, este trabalho busca contribuir para estes estudos.

As características da administração pública gerencial estão em funcionamento no âmbito do Prêmio Inoves por meio de mecanismos incentivados pelo programa, como o estímulo ao empreendedorismo e práticas utilizadas pelos projetos premiados. As lógicas do processo de reestruturação capitalista, da burocracia, do gerencialismo e outros alcançam as políticas, a cultura e as estruturas das organizações de Estado. Dessa forma, os mecanismos que regem as empresas privadas, buscando agilidade, maior eficiência e qualidade nos serviços, são, por vezes, incorporados ao Estado (Ribeiro \& Mancebo, 2013).

A possibilidade de divulgar para a sociedade a realização de projetos que proporcionaram benefícios no setor público está entre as razões que impulsionam os servidores a participarem do Prêmio.

Com isso, percebe-se a relevância do Prêmio Inoves para a sociedade, além dos servidores públicos alcançados pelo programa, devido à iniciativa governamental que enaltece experiências exitosas criadas por servidores públicos.

\section{REFERÊNCIAS}

Abreu, F. S. (1994, Setembro/Outubro). Reengenharia - em busca de uma teoria. Revista de Administração de Empresas (RAE), 34(5), 49-61.

Bardin, L. (2004). Análise de conteúdo. (3 ed). Lisboa: Edições 70.

Bauer, M. W.; Gaskell, G.; Allum, N. C. (2002). Qualidade, quantidade e interesses do conhecimento - evitando confusões. In: Bauer, M. W.; Gaskell, G. Pesquisa qualitativa com texto, imagem e som. Rio de Janeiro: Vozes, 1, 17-36. 
Beinare, D.; McCarthy, M. (2011, Novembro). Civil society organisations, social innovation and health research in Europe. European Journal of Public Health, 22(6), 889-893.

Borins, S. (2000). What Border? Public Management Innovation in the United States and Canada. Journal of Policy Analysis and Management, 19(1), 46-74.

Borins, S. (2001). Encouraging innovation in the public sector. Emerald: Journal of Intellectual Capital, 2(3), 310-319.

Brandão, S. M.; Bruno-Faria, M. F. (2013, Janeiro/Fevereiro). Inovação no setor público: análise da produção científica em periódicos nacionais e internacionais da área de administração. Revista da Administração Pública, 47(1), 227-248.

Bresser-Pereira, L. C. (1998). Gestão do setor público: estratégia e estrutura para um novo Estado. In: Bresser-Pereira, L. C.; Spink, P. K. (Orgs.). Reforma do Estado e Administração Pública Gerencial. (1. ed). Rio de Janeiro: Fundação Getúlio Vargas, 21-38.

Bresser-Pereira, L. C. (2000, Julho/Agosto). A reforma gerencial do Estado de 1995. RAP. Rio de Janeiro, 7-26.

Carvalho, E. J. G. (2009, Setembro/Dezembro). Reestruturação produtiva, reforma administrativa do estado e gestão da educação. Educ. Soc., 30(109), 1139-1166.

Castro, C. M. S.; Isidoro-Filho, A.; Menelau, S.; Fernandes, A. S. A. (2017). Antecedentes de inovações em organizações públicas do poder executivo federal. Cadernos Gestão Pública e Cidadania, 22(71), 128-143.

Chanlat, J. F. (2002). O gerencialismo e a ética do bem-comum: a questão da motivação para o trabalho nos serviços públicos. In: VII Congreso Internacional del CLAD sobre la Reforma del Estado y de la Administración Pública. Anais, Lisboa, Portugal.

Colbari, A. (2014). A análise de conteúdo e a pesquisa empírica qualitativa. In: SOUZA, E. M. (Org.). Metodologias e analíticas qualitativas em pesquisa organizacional: uma abordagem teórico-conceitual. Dados eletrônicos: EDUFES, 241-274.

Editorial: efeito multiplicador. (2006). Revista INOVES, 2(3).

Franco, M. L. P. B. (2003). Análise de conteúdo. Brasília: Plano.

Hansson, F.; Norn, M. T.; Vad, T. B. (2014). Modernize the public sector through innovation? A challenge for the role of applied social science and evaluation. Evaluation, 20(2), 244-260. 
Hondeghem, A.; Dorpe, K. V. (2013). Performance management systems for senior civil servants: How strong is the managerial public service bargain? International Review of Administrative Sciences, 79(1), 9-27.

Hughes, A.; Moore, K.; Kataria, N. (2011). Innovation in public sector organisations: a pilot survey for measuring innovation across the public sector. Recuperado de https://www.bl.uk/collection-items/innovation-in-public-sector-organisations-a-pilot-survey-for-measuring-innovation-across-the-public-sector.

Inoves. (2019, Maio). Categorias. Recuperado de https://inoves.es.gov.br/ categorias.

Lima, D. H.; Vargas, E. R. (2012, Março/abril). Estudos internacionais sobre inovação no setor público: como a teoria da inovação em serviços pode contribuir? Revista de Administração Pública (RAP), 46(2), 385-401.

Menos burocracia, mais informação. (2013). Revista Inoves, 9, 20-21.

Motta, P. R. M. (2013, Janeiro/Fevereiro). Pensata - O estado da arte da gestão pública. RAE, 53(1), 82-90.

Potts, J.; Kastelle, T. (2010). Public sector innovation research: what's next? Innovation: Management, Policy \& Practice Journal, 12(2), 122-137.

Prêmio Inoves. (2019, Abril). Prêmio Inovação na Gestão Pública do Estado do Espírito Santo. Ciclo 2015. Recuperado de http://www.Inoves.es.gov.br/Premio/Inicio.aspx.

Ribeiro, C. V. S.; Mancebo, D. (2013). O Servidor Público no Mundo do Trabalho do Século XXI. Psicologia: Ciência e Profissão, 33(1), 192-207.

Rosenblatt, M. (2011). The use of innovation awards in the public sector: individual and organizational perspectives. Innovation: management, policy \& practice. 13(2).

Santos, A. F. (2017, Julho). Evolução dos Modelos de Administração Pública no Brasil. Revista Científica Multidisciplinar Núcleo do Conhecimento, 4(1), 848-857.

Santos, A. F. (2018, Agosto). Administração Pública Brasileira. O Modelo Gerencial e as Ferramentas de Melhoria na Gestão Pública. Revista Científica Multidisciplinar Núcleo do Conhecimento, 8(4), 69-85.

Santos, L. F.; Sano, H.; Souza, W. J. (2019). Antecedentes da inovação na gestão pública: Análise de experiências inovadoras do setor rural brasileiro. Revista Eletrônica Gestão \& Sociedade, 13(35), 2870-2900.

Silva, A. S.; Macedo, L. N.; Andrade, H. (2013). Gestão Pública Empreendedora: uma análise na Secretaria Municipal de Educação em Curuçá - PA. Amazô- 
nia em Foco. Empreendedorismo e Sustentabilidade, 1, 117-159.

Sousa, M. M.; Ferreira, V. R. S.; Najberg, E.; Medeiros, J. J. (2013). Inovação no Serviço Público Brasileiro: Análise de 16 Edições do Concurso de Inovação na Administração Pública Federal. Rio de Janeiro: EnANPAD.

Sousa, M. M.; Ferreira, V. R. S.; Najberg, E.; Medeiros, J. J. (2015). Portraying innovation in the public service of Brazil: Frameworks, systematization and characterization. Revista de Administração, 50(4), 460-476.

Teixeira, T. S.; Andrade, D. M.; Alcântara, V. C.; Oliveira, N. K. (2019, Janeiro/ Março). Inovação e Empreendedorismo: Um caso no setor público. Pretexto, 20(1), 57-71.

Um tributo à inovação, à criatividade e ao talento. (2013). Revista Inoves, 9, 06-09.

Walker, R. M.; Damanpour, F.; Devece, C. A. (2010). Management innovation and organizational performance: the mediating effect of performance management. Journal of Public Administration Research and Theory. Recuperado de http://jpart.oxfordjournals.org/content/early/2010/08/18/jopart.muq043. full.pdf+html,

Wodecka-Hyjek, A. (2014). A learning public organization as the condition for innovations adaptation. Procedia - Social and Behavioral Sciences, 110, 148-155.

Yin, R. K. (2016). Pesquisa qualitativa do início ao fim. Porto Alegre: Penso Editora. 